\title{
Oxidation of Methylmalonic Acid by Cerium(IV). Evidence for Parallel Reaction Pathways
}

\author{
Per Olav Kvernberg, ${ }^{\dagger}$ Eddy W. Hansen,,$\stackrel{ }{\ddagger}$ Bjørn Pedersen, ${ }^{\dagger}$ Asbjørn Rasmussen, ${ }^{\dagger}$ and \\ Peter Ruoff*, $\$$ \\ Department of Chemistry, University of Oslo, P.O. Box 1033 Blindern, N-0315 Oslo, Norway, SINTEF Oslo, \\ P.O. Box 124 Blindern, N-0314 Oslo, Norway, and School of Technology and Science, Stavanger College, \\ P.O. Box 2557 Ullandhaug, N-4004 Stavanger, Norway
}

Received: October 24, 1996; In Final Form: January 21, $1997^{\otimes}$

\begin{abstract}
The reaction between methylmalonic acid (MeMA) and $\mathrm{Ce}(\mathrm{IV})$ ion in $1 \mathrm{M}$ sulfuric acid/ $\mathrm{D}_{2} \mathrm{SO}_{4}$ has been studied by means of ${ }^{1} \mathrm{H}$ - and ${ }^{13} \mathrm{C}-\mathrm{NMR}$. When MeMA is in excess, acetic acid, hydroxymethylmalonic acid, and pyruvic acid are formed as stable end products. When Ce(IV) is in stoichiometric excess, acetic acid is the only product. Approximately $70-80 \%$ of the MeMA forms rapidly acetic acid with hydroxymethylmalonic acid and pyruvic acid as reactive intermediates. The remaining MeMA reacts along parallel pathways and forms two intermediates, which slowly convert to hydroxymethylmalonic acid and pyruvic acid, respectively.
\end{abstract}

\section{Introduction}

$\mathrm{Ce}(\mathrm{IV})$ compounds are important oxidants in many fields of chemistry. ${ }^{1-5}$ In the Belousov ${ }^{6}-$ Zhabotinsky $^{7}(\mathrm{BZ})$ reaction, ${ }^{8}$ $\mathrm{Ce}$ (IV) oxidation of aliphatic organic substrates that contain a reactive $\mathrm{C}-\mathrm{H}$ bond, as in malonic acid and derivatives, is a necessary component process for obtaining sustained concentration oscillations. While the inorganic mechanism for the oscillatory BZ reaction is well established ${ }^{9,10}$ and has successfully been modeled by the Oregonator ${ }^{11}$ and related models, ${ }^{12}$ still little is known about the reactions of the organic subset. Considerable "detective work" is necessary to identify the various components in this subset. ${ }^{13,14}$

The methylmalonic acid (MeMA) BZ reaction ${ }^{15}$ has shown a variety of unusual dynamical behaviors such as excitabilities of oxidized and reduced steady states and even bistability in a closed system. ${ }^{16}$ A kinetic study of the reaction between MeMA and $\mathrm{Ce}(\mathrm{IV})$ has been performed by Ruoff and Nevdal ${ }^{17}$ mainly by using initial rates and UV spectroscopy. Although the stoichiometry of the Ce(IV)-MeMA reaction is expected to be

$$
\begin{aligned}
& \mathrm{CH}_{3} \mathrm{CH}(\mathrm{COOH})_{2}+6 \mathrm{Ce}(\mathrm{IV})+2 \mathrm{H}_{2} \mathrm{O} \rightarrow \\
& \mathrm{CH}_{3} \mathrm{COOH}+6 \mathrm{Ce}(\mathrm{III})+6 \mathrm{H}^{+}+2 \mathrm{CO}_{2}
\end{aligned}
$$

iodometric analysis showed that during a $20 \mathrm{~h}$ period only 4.7 mol of Ce(IV) were consumed per mole of MeMA. ${ }^{17}$ Ruoff and Nevdal also found that under certain conditions a precipitate appeared, while the recorded ${ }^{1} \mathrm{H}-\mathrm{NMR}$ spectrum of the reaction mixture showed an unidentified product together with pyruvic acid as a probable intermediate.

Earlier NMR investigations on MeMA-BZ systems and subsystems ${ }^{18,19}$ encouraged us to study in further detail the MeMA-Ce(IV) system. In this paper we report new results where intermediates and products of the MeMA-Ce(IV) reaction were followed quantitatively with different initial concentrations. It was found that most of the MeMA $(\sim 70-$ $80 \%$ ) reacts rapidly to form acetic acid (HOAc). For this main pathway NMR spectra indicate the presence of small amounts of hydroxymethylmalonic acid (MeMAOH) and pyruvic acid (Pyr), as reactive intermediates. The remaining MeMA reacts

\footnotetext{
$\dagger$ University of Oslo.

SINTEF Oslo.

\$ Stavanger College.

${ }^{\otimes}$ Abstract published in Advance ACS Abstracts, March 1, 1997.
}

by another route, where two additional intermediates form. These intermediates react slowly by first-order processes to form respectively MeMAOH and Pyr with half-lives of 6-8 h.

\section{Experimental Section}

MeMA was purchased from Fluka ( $>99 \%$ ) and dissolved in $1 \mathrm{M} \mathrm{H}_{2} \mathrm{SO}_{4}$ (Merck) or $\mathrm{D}_{2} \mathrm{SO}_{4} / \mathrm{D}_{2} \mathrm{O}$ solution (Norsk Hydro). The purity of MeMA was checked by ${ }^{1} \mathrm{H}-\mathrm{NMR}$. Reacting solutions were made by dissolving $\left(\mathrm{NH}_{4}\right)_{2} \mathrm{Ce}\left(\mathrm{NO}_{3}\right)_{6}$ (Merck, analytical quality) in $\mathrm{H}_{2} \mathrm{SO}_{4}$ or $\mathrm{D}_{2} \mathrm{SO}_{4}$ and adding a corresponding solution of MeMA. The reaction volume was $5 \mathrm{~mL}$.

${ }^{1} \mathrm{H}$ - and ${ }^{13} \mathrm{C}$-NMR spectra were recorded on a Varian XL 300 spectrometer. Sixty four scans were accumulated with a sweep width of $4000 \mathrm{~Hz}$, a repetition time of $3.752 \mathrm{~s}$, and a pulse angle of $17^{\circ}$. All NMR measurements were performed at $23 \pm 2{ }^{\circ} \mathrm{C}$. Because the chemical shifts are affected by the presence of paramagnetic $\mathrm{Ce}(\mathrm{III})$ ions, peaks were identified by adding the compound in question to the solution and observing a corresponding increase in the peak intensity. Partly overlapping peaks were resolved with the program PEAKFIT. ${ }^{20}$

In the experiments reported here we have not excluded atmospheric oxygen from the reaction solution. A test where oxygen was removed by Ar-bubbling through initial reagent solutions and through the reaction mixture during a NMR run showed very similar kinetics of the same intermediates and final products as under aerobic conditions. Although this indicates that oxygen probably has little effect on the $\mathrm{Ce}(\mathrm{IV})-\mathrm{MeMA}$ reaction, more detailed studies are necessary to look for possible oxygen effects.

MeMAOH was synthesized using the method by An et al. ${ }^{21}$ The purity of the MeMAOH was tested with ${ }^{1} \mathrm{H}$ - and ${ }^{13} \mathrm{C}-\mathrm{NMR}$.

The presence of $\mathrm{Ce}(\mathrm{III})$ in a formed precipitate was found by electron-emission spectroscopy using a Philipps 515 scanning electron microscope.

Simulation calculations were done by using the programs FACSIMILE/CHECKMAT ${ }^{22}$ and the FORTRAN subrouine LSODE. $^{23}$

\section{Experimental Observations}

Stoichiometric Excess of MeMA. In a Ce(IV)-MeMA solution the main product is acetic acid (HOAc). Besides HOAc two new intermediates "preMeMAOH" and "prePyr" have been found (Figure 1). After about $1.5 \mathrm{~h}\left([\mathrm{Ce}(\mathrm{IV})]_{0}=0.2 \mathrm{M}\right.$, 


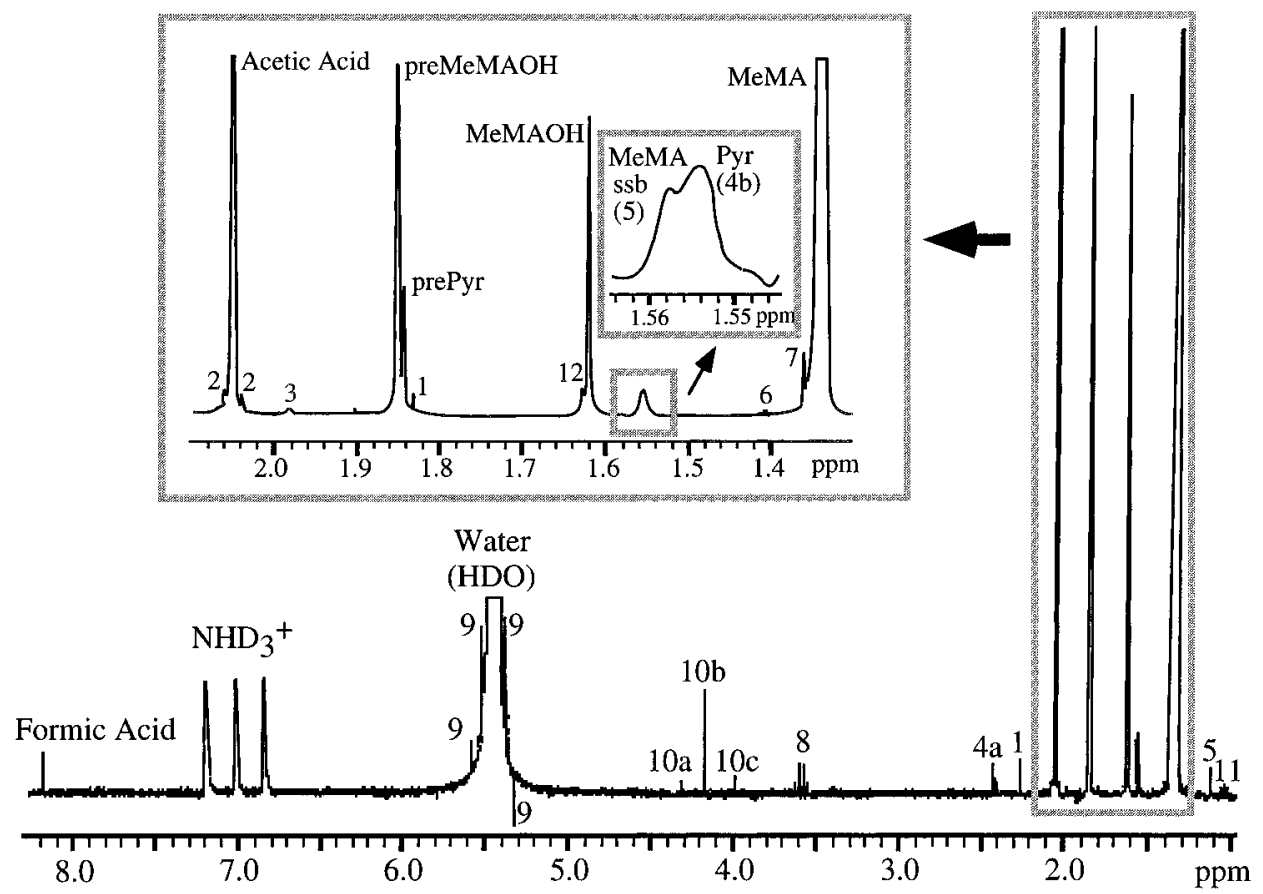

Figure 1. ${ }^{1} \mathrm{H}-\mathrm{NMR}$ spectrum of a $0.1 \mathrm{M} \mathrm{MeMA}$ and $0.2 \mathrm{M} \mathrm{Ce}(\mathrm{IV})$ reaction solution in $1 \mathrm{M} \mathrm{D}_{2} \mathrm{SO}_{4}$ taken $7.7 \mathrm{~h}$ after the start of reaction. Peak identification: (1) HOAc satellites caused by ${ }^{13} \mathrm{CH}_{3}{ }^{12} \mathrm{COOH}$ coupling; (2) $\mathrm{HOAc}$ satellites caused by ${ }^{12} \mathrm{CH}_{3}{ }^{13} \mathrm{COOH}$ coupling; (3) $\mathrm{HOAc}$ spinning sidebands; (4a) Pyr (keto-form); (4b) Pyr (diol-form) superimposed on MeMA satellite; (5) MeMA satellite due to ${ }^{13} \mathrm{CH}{ }_{3}^{12} \mathrm{CH}(\mathrm{COOH})_{2}$ coupling; (6) MeMA spinning sidebands; (7) one of the doublet peaks of nondeuterated MeMA $\left(\mathrm{CH}_{3} \mathrm{CH}(\mathrm{COOH})_{2}\right.$; (8) quartet caused by nondeuterated MeMA $\left(\mathrm{CH}_{3} \mathrm{CH}(\mathrm{COOH})_{2}\right)$; (9) spinning sideband of the water peak; $(10,11,12)$ unidentified peaks.
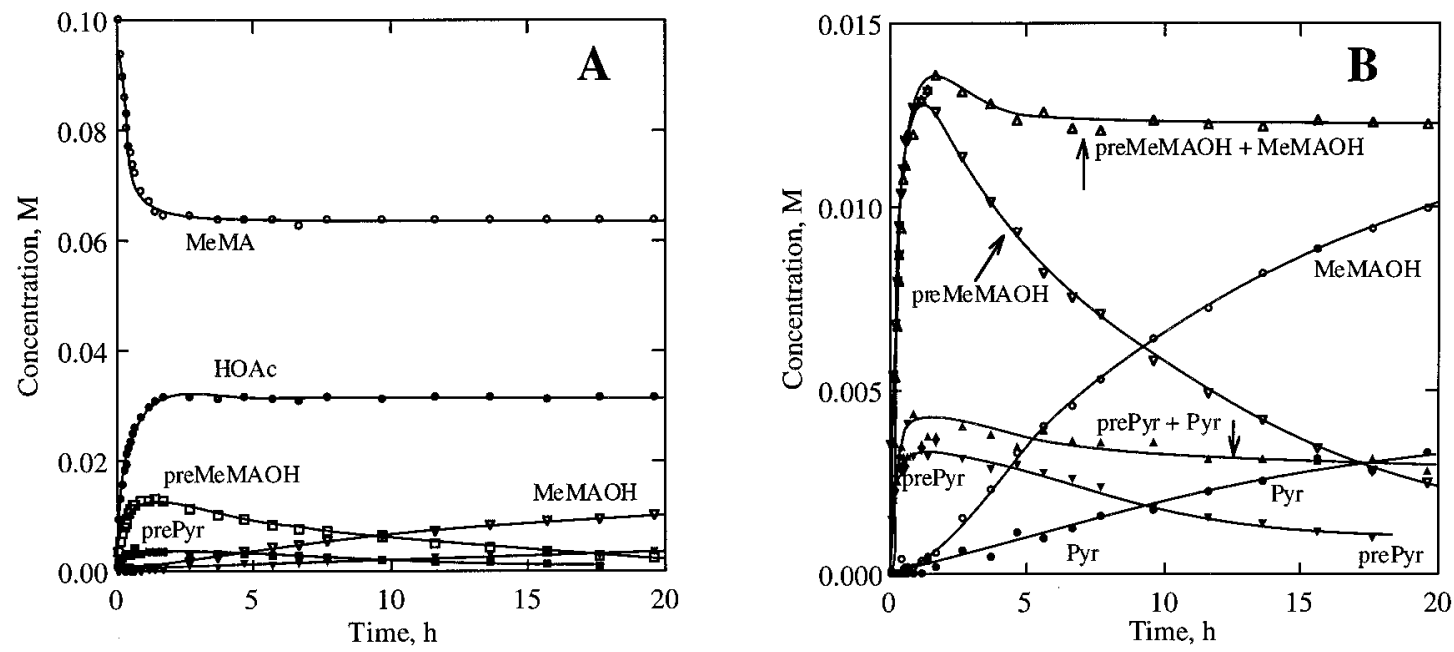

Figure 2. (A) Concentration profiles of a $0.1 \mathrm{M}$ MeMA and $0.2 \mathrm{M} \mathrm{Ce}(\mathrm{IV})$ reaction solution in $1 \mathrm{M} \mathrm{D}_{2} \mathrm{SO}_{4}$ recorded during the first $20 \mathrm{~h}$. (B) Concentration changes in preMeMAOH, MeMAOH, prePyr, Pyr, preMeMAOH + MeMAOH, and prePyr + Pyr for the same system as in A. Note that preMeMAOH $+\mathrm{MeMAOH}$ and prePyr $+\mathrm{Pyr}$ remain practically constant after the respective maxima of preMeMAOH and prePyr have been reached.

$\left.[\mathrm{MeMA}]_{0}=0.1 \mathrm{M}\right)$ the HOAc and MeMA concentrations reach constant values, indicating that all Ce(IV) has been consumed. At this point preMeMAOH and prePyr concentrations reach their maxima (Figure 2), and then they decay slowly, by first-order processes, to MeMAOH and pyruvic acid (Pyr), respectively (Figure 3). A quantitative analysis shows that the sums of preMeMAOH $+\mathrm{MeMAOH}$ concentrations and prePyr $+\mathrm{Pyr}$ concentrations are practically constant, indicating that the "preforms" are indeed precursors of MeMAOH or Pyr (Figure 2B). After approximately $40 \mathrm{~h}$ preMeMAOH and prePyr disappeared and the system reached equilibrium. When MeMA is in stoichiometric excess, the only products are HOAc, MeMAOH, and Pyr. Small amounts of formic acid have been observed to appear rapidly in the beginning of the reaction (Figure 1). However, once formed, the formic acid concentration remains unchanged until the end of the reaction.
Figure 4 shows equilibrium concentrations of $\mathrm{HOAc}, \mathrm{Me}-$ $\mathrm{MAOH}, \mathrm{Pyr}$, and MeMA when the initial MeMA concentration is $0.05 \mathrm{M}$ with varying initial $\mathrm{Ce}(\mathrm{IV})$ concentrations. Solid lines show the results of model computations (see below). It was found that as long as the initial MeMA concentration is in stoichiometric excess, the number of moles of consumed Ce(IV) per mole MeMA lies in the range 4.5-5.0. Interestingly, this value is in the same range as found previously $(4.7)^{17}$ by iodometric analysis when Ce(IV) was in 10-fold molar excess over MeMA.

Excess of $\mathbf{C e}(\mathrm{IV})$. When more than 6 equiv of $\mathrm{Ce}(\mathrm{IV})$ are present, all MeMA reacts to form HOAc. However, also in this case we see the buildup and decay of preMeMAOH and prePyr, but now only very small equilibrium concentrations of MeMAOH or Pyr could be detected. Also here traces of formic acid appear early in the reaction and remain constant until 


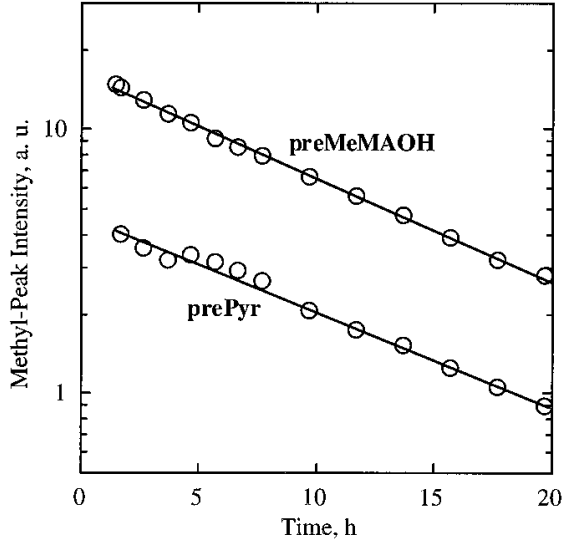

Figure 3. Intermediates preMeMAOH and prePyr show a first-order decay after they have reached their maximum at the end of the $\mathrm{Ce}$ (IV) consumption period. Decay constants: $k_{\text {preМемаон }}=0.091 \mathrm{~h}^{-1}(r=$ $0.9982), k_{\text {prePyr }}=0.084 \mathrm{~h}^{-1}(r=0.9892)$.

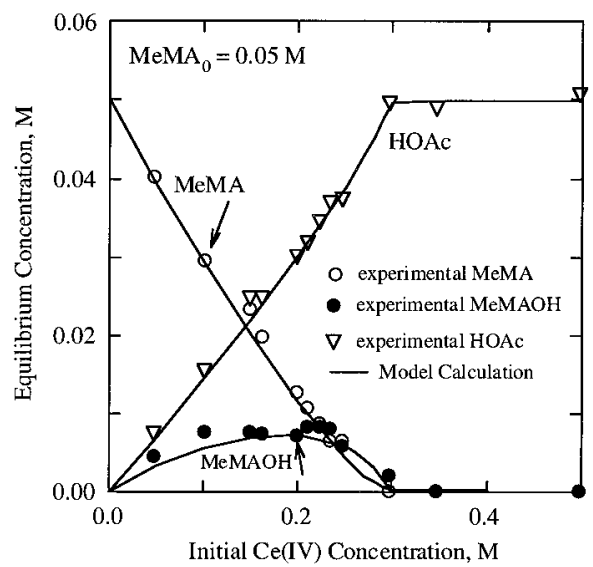

Figure 4. Experimental and computed equilibrium concentrations. Initial MeMA concentration is $0.05 \mathrm{M}$. Solid lines combine calculated equilibrium concentrations with $[\mathrm{Ce}(\mathrm{IV})]_{0}$ increments of $0.05 \mathrm{M}$. Near $[\mathrm{Ce}(\mathrm{IV})]_{0}=0.3 \mathrm{M}$ the increment was $0.01 \mathrm{M}$. Model (Scheme 4) computations were performed using the same rate constant values as in Figure 8.

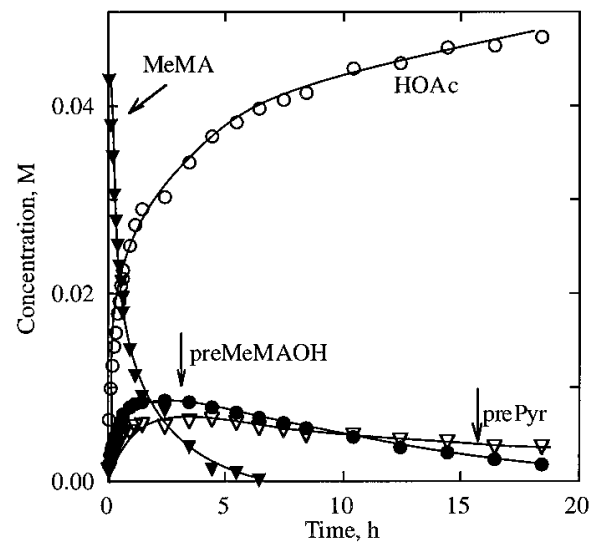

Figure 5. Concentration profiles of a $0.05 \mathrm{M} \mathrm{MeMA}$ and $0.4 \mathrm{M} \mathrm{Ce}-$ (IV) reaction solution in $1 \mathrm{M} \mathrm{D}_{2} \mathrm{SO}_{4}$ recorded during the first $20 \mathrm{~h}$. The first-order decay constants for preMeMAOH and prePyr are $k_{\text {preMемАОН }}=0.039 \mathrm{~h}^{-1}(r=0.9423) ; k_{\text {prePyr }}=0.105 \mathrm{~h}^{-1}(r=0.9888)$.

equilibrium is reached. We consider formic acid to originate rapidly from small malonic acid impurities in the MeMA. ${ }^{24}$

Figure 5 shows the concentration profiles of a reacting system with initial concentrations of $0.05 \mathrm{M}$ MeMA and $0.4 \mathrm{M} \mathrm{Ce}(\mathrm{IV})$. In such a system even after $20 \mathrm{~h}$ significant amounts of preMeMAOH and prePyr are still present.
SCHEME 1<smiles>[CH]OC(O)C(C)C(O)O[CH]</smiles>

Other Reactions. We have tried to follow the reactions between $\mathrm{Ce}(\mathrm{IV})$ and MeMAOH or Pyr by NMR, but these reactions are too fast and were finished before the sample could be inserted into the spectrometer.

As reported earlier, ${ }^{17}$ the formation of a white precipitate was observed, especially at an initial $[\mathrm{MeMA}]_{0} /[\mathrm{Ce}(\mathrm{IV})]_{0}$ ratio of 1:4. Sometimes, instead of an insoluble solid matrix, ${ }^{17}$ crystals are observed. Electron-emission spectroscopy of the precipitate showed unequivocally the presence of $\mathrm{Ce}$, indicating a $\mathrm{Ce}$ (III) compound, which we consider to be $\mathrm{Ce}\left(\mathrm{NH}_{4}\right) \mathrm{SO}_{4}$.

Unidentified Peaks. We have not been able to identify peaks 10, 11, and 12 (Figure 1), but corresponding intermediates/ products must be present in quite small amounts.

\section{Discussion and Model Calculations}

Comparison with Iodometric Results. Ruoff and Nevdal ${ }^{17}$ have studied the stoichiometry of process R1 by measuring the amount of consumed Ce(IV) during an approximately $20 \mathrm{~h}$ reaction period when $\mathrm{Ce}$ (IV) was in 10-fold molar excess over MeMA. It was found that only $4.7 \mathrm{~mol}$ of $\mathrm{Ce}(\mathrm{IV})$ reacted for each mole of MeMA. An explanation of the discrepancy between the previous ${ }^{17}$ findings and the present observation that under stoichiometric excess of $\mathrm{Ce}(\mathrm{IV})$ all MeMA reacts to HOAc is that a $20 \mathrm{~h}$ period is not sufficient (Figure 5) for process $\mathrm{R} 1$ to reach equilibrium.

Kinetic Considerations. The previous studies ${ }^{17}$ also showed that the $\mathrm{Ce}(\mathrm{IV})-\mathrm{MeMA}$ reaction, in analogy with the corresponding malonic acid reaction, ${ }^{25}$ follows a sequential mechanism with probably an initial complexation between $\mathrm{Ce}(\mathrm{IV})$ and methylmalonic acid (Scheme 1)..$^{5,26-28}$

In an earlier proposed reaction scheme ${ }^{17}$ it was assumed that MeMAOH originates from methylmalonyl radicals only. The present findings (Figure 2B) clearly show that also preMe$\mathrm{MAOH}$ is a precursor of MeMAOH. However, the rather long half-life of preMeMAOH makes it unlikely that this compound is related to any radical species!

In view of the above results, we propose the existence of parallel reaction pathways from MeMA to acetic acid (Figure 6). The main route forms rapidly HOAc via MeMAOH and Pyr as reactive intermediates. The remaining MeMA reacts by separate pathways via preMeMAOH and prePyr.

Further support for this interpretation can be obtained by analyzing the initial rates forming $\mathrm{HOAc}$, preMeMAOH, and prePyr. In the case of parallel reaction channels " $i$ " with identical or similar reaction orders in Ce(IV) and MeMA, the quotients of reaction velocities $v_{i} / v_{k}$ should be constant. In other words, there should be an intrinsic proportionality between concentrations of produced species for each channel. Figure 7 shows that this is in fact the case: a plot of [preMeMAOH] and [prePyr] against [HOAc] gives two straight lines as long as $\mathrm{HOAc}$, preMeMAOH, and prePyr are produced.

Possible Chemical Nature of preMeMAOH and prePyr. Compared with MeMAOH and Pyr, the increased chemical shifts of the methyl group in preMeMAOH and prePyr (Figure 1) suggest the presence of electron-withdrawing groups. A possibility may be that $\mathrm{Ce}(\mathrm{IV})$ in complexes like in Scheme 1 


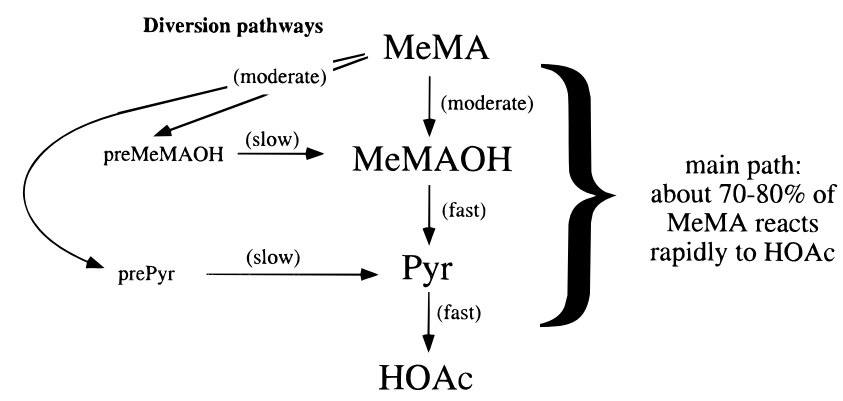

Figure 6. Proposed diversions from the main reaction path in the $\mathrm{Ce}(\mathrm{IV})$ oxidation of MeMA.

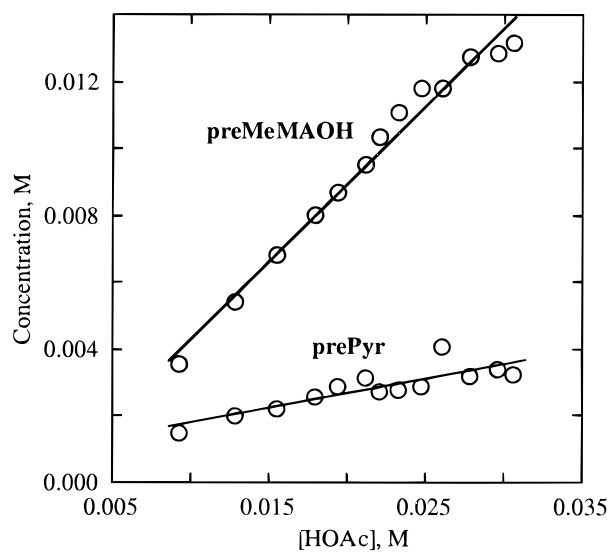

Figure 7. Concentrations of formed preMeMAOH and prePyr in relation to formed HOAc during the first $1.5 \mathrm{~h}$ of the reaction shown in Figure 2. The linear relationship suggests an additional parallel path from MeMA forming preMeMAOH and prePyr.

SCHEME 2

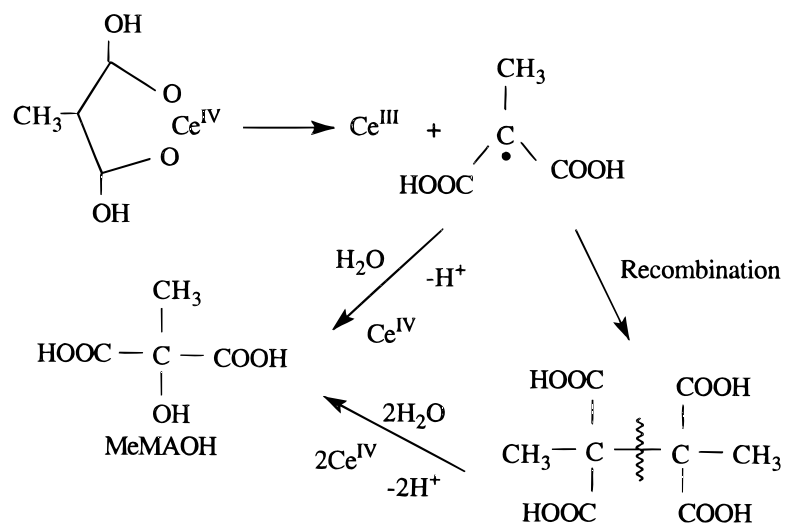

leads to an increase in the chemical shift of the methyl group and that preMeMAOH and prePyr may correspond to less reactive $\mathrm{Ce}(\mathrm{IV})$ complexes of MeMAOH or Pyr.

The work of Gao et al. ${ }^{13}$ and Sirimungkala et al. ${ }^{14}$ have identified a variety of possible radical recombination products in the $\mathrm{Ce}(\mathrm{IV})-$ malonic acid reaction. Similarily, preMeMAOH and prePyr may be related to analogous recombination products. In the case of preMeMAOH the deviation pathway may be due to methylmalonyl radical recombination. The main pathway is assumed to be the hydrolysis of methylmalonyl radicals forming MeMAOH (Scheme 2). For the "prePyr pathway" the deviation may occur in a similar manner, where the one-electron oxidation of $\mathrm{CH}_{3} \mathrm{C}^{\bullet}(\mathrm{OH}) \mathrm{COOH}$ radicals represents the main path (Scheme 3).

It should be noted, that the two Ce(IV) equivalents needed to oxidize the radical recombination products to MeMAOH and Pyr (Schemes 2 and 3) must be incorporated in preMeMAOH and prePyr, because no further acetic acid is formed during the

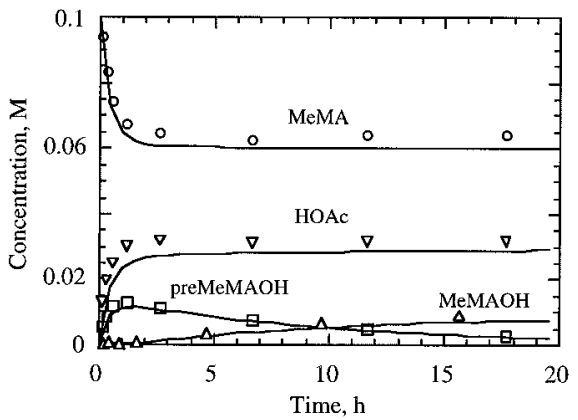

Figure 8. Model computations testing the kinetic behavior of the model (Scheme 4). Initial concentrations: $[\mathrm{MeMA}]_{0}=0.1 \mathrm{M},[\mathrm{Ce}(\mathrm{IV})]_{0}=$ $0.2 \mathrm{M}$. Rate constant values: $k_{1}=2.5 \mathrm{M}^{-1} \mathrm{~h}^{-1}, k_{2}=3.1 \mathrm{M}^{-1} \mathrm{~h}^{-1}, k_{3}$ $=1000 \mathrm{M}^{-1} \mathrm{~h}^{-1}, k_{4}=0.1 \mathrm{~h}^{-1}, k_{5}=500 \mathrm{M}^{-1} \mathrm{~h}^{-1}, k_{6}=2000 \mathrm{M}^{-1} \mathrm{~h}^{-1}$. Symbols indicate experimental results.

\section{SCHEME 3}<smiles>CC(O)(C(=O)O)C(=O)O</smiles><smiles>CC(O)(C(=O)O)[14C](=O)O[Na]</smiles>

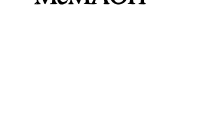<smiles>CCC1CC1</smiles>

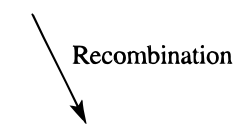<smiles>CC(=O)C(=O)O</smiles><smiles>CC(O)(C(=O)O)C(C)(O)C(=O)O</smiles>

\section{SCHEME 4}

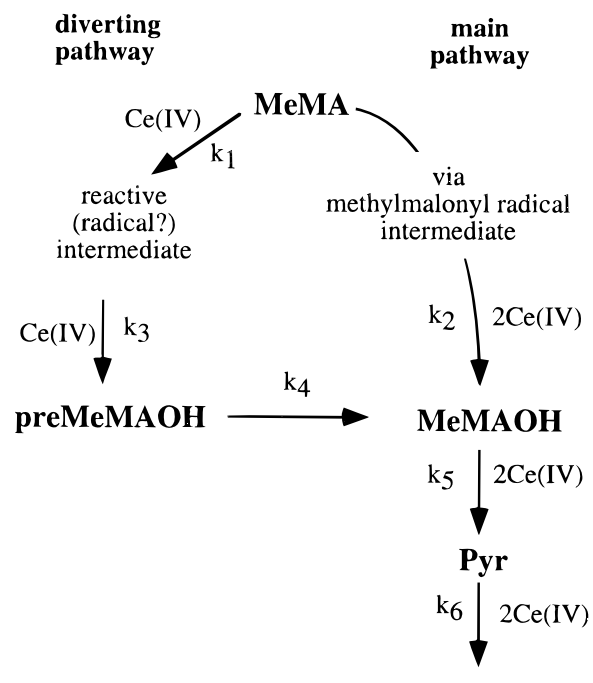

HOAc

decay of the preforms to MeMAOH and Pyr. It may be possible that the preforms of $\mathrm{MeMAOH}$ and Pyr are complexes between two $\mathrm{Ce}(\mathrm{IV})$ ions and $\left(\mathrm{CH}_{3} \mathrm{C}(\mathrm{COOH})_{2}\right)_{2}$ (forming preMeMAOH) or two $\mathrm{Ce}(\mathrm{IV})$ and $\left(\mathrm{CH}_{3} \mathrm{C}(\mathrm{COOH})(\mathrm{OH})\right)_{2}$ (forming prePyr). In the case of preMeMAOH each of the two $\mathrm{Ce}(\mathrm{IV})$ may interact with both sets of the adjacent carboxyl groups, analogous to the $\mathrm{Ce}(\mathrm{IV})-\mathrm{MeMA}$ complex (Scheme 1). In prePyr, one $\mathrm{Ce}(\mathrm{IV})$ may bind to the two $\mathrm{COOH}$ groups, while the other $\mathrm{Ce}(\mathrm{IV})$ may form a complex with the $\mathrm{OH}$ groups. ${ }^{29}$ Also recombinations between radical species $\mathrm{CH}_{3} \mathrm{C}^{\bullet}(\mathrm{COOH})_{2}$ (Scheme 2) and $\mathrm{CH}_{3} \mathrm{C}^{\bullet}(\mathrm{COOH})(\mathrm{OH})$ (Scheme 3$)$ may be possible, and we wonder whether some of the unidentified peaks are related to "mixed" radical recombination products. 
A Simple Model. To test the kinetic behavior of a parallel reaction pathway, we have, for the case of preMeMAOH, studied a simple model (Scheme 4). Because prePyr and Pyr are present in low concentrations, we have not included them in the calculations. All processes are assumed to be first-order in $\mathrm{Ce}(\mathrm{IV})$ and organic substrates, respectively.

To account for linear double-reciprocal plots, ${ }^{17}$ a rapid equilibrium between complexed and uncomplexed MeMA has to be assumed (Scheme 1). Although complexed and uncomplexed MeMA could in principle be observed by NMR, a rapid equilibrium will result in only one "average" ${ }^{1} \mathrm{H}$-methyl peak (as is observed). In the model we have so far not distinguished between uncomplexed and Ce(IV)-complexed MeMA and $\mathrm{MeMAOH}$. The formation of $\mathrm{Pyr}$ and $\mathrm{HOAc}$ are rapid processes, while $k_{1}, k_{2}$, and $k_{4}$ are rate determining.

Practically quantitative agreement can be obtained between this simple model and experiments (Figure 4 and Figure 8) showing that the parallel reaction pathway gives an adequate description.

However, further work will be needed to understand in more detail the chemistry of the radical and nonradical interactions and their significance in the dynamic behavior of MeMA-BZ systems.

Acknowledgment. We thank Ola Risvik at Stavanger College for recording the electron-emission spectra.

\section{References and Notes}

(1) Willard, H. H.; Young, P. J. Am.Chem. Soc. 1930, 52, 132

(2) Smith, G. F. Cerate Oxidimetry; The G. Frederick Smith Chemical Co.: Columbus, $\mathrm{OH}, 1942$.

(3) Richardson, W. H. In Oxidation in Organic Chemistry; Wiberg, K. G., Ed.; Academic Press: New York, 1965.

(4) Ho, T.-L. Synthesis 1973, 347.
(5) Cotton, F. A.; Wilkinson, G. Advanced Inorganic Chemistry; Interscience: New York, 1972.

(6) Belousov, B. P. In Oscillations and Traveling Waves in Chemical Systems; Field, R. J., Burger, M., Eds.; Wiley: New York, 1985.

(7) Zhabotinsky, A. M. In Oscillations and Traveling Waves in Chemical Systems; Field, R. J., Burger, M., Eds.; Wiley: New York, 1985. (8) Noyes, R. M. J. Phys. Chem. 1990 94, 4404. 8649.

(9) Field, R. J.; Körös, E.; Noyes, R. M. J. Am. Chem. Soc. 1972, 94,

(10) Ruoff, P.; Varga, M.; Körös, E. Acc. Chem. Res. 1988 21, 326.

(11) Field, R. J.; Noyes, R. M. J. Chem. Phys. 1974, 60, 1877.

(12) Tyson, J. J. In Oscillations and Traveling Waves in Chemical Systems; Field, R. J., Burger, M., Eds.; Wiley: New York, 1985.

(13) Gao, Y.; Försterling, H.-D.; Noszticzius, Z.; Meyer, B. J. Phys. Chem. 1994, 98, 8377.

(14) Sirimungkala, A.; Försterling, H.-D.; Noszticzius, Z. J. Phys. Chem. 1996, 100,3051 .

(15) Ruoff, P.; Schwitters, B. Z. Phys. Chemie (Wiesbaden) 1983, 135, 171.

(16) Ruoff, P.; Noyes, R. M. J. Phys. Chem. 1985, 89, 1339.

(17) Ruoff, P.; Nevdal, G. J. Phys. Chem. 1989, 93, 7802. 682 .

(18) Hansen, E. W.; Gran, H. C.; Ruoff, P. J. Phys. Chem. 1985, 89,

(19) Hansen, E. W.; Ruoff, P. J. Phys. Chem. 1989, 93, 2696.

(20) PEAKFIT ver 2.0; Jandel Scientific Europe, P.O.B. 4107, D-40688 Erkrath, Germany, 1989.

(21) An, Z.; Rino, A.; Venturello, C. Synthesis (Stuttgart) 1992, March issue, 273.

(22) FAKSIMILE/CHECKMAT; Harwell Laboratory Computer Science and System Division: Oxfordshire, Oxon OX11 ORA, England, 1988.

(23) Hindmarsh, A. C. ACM-SIGNUM Newslett. $198015,10$.

(24) (a) Willard, H. H.; Young, P. J. Am. Chem. Soc. 1930, 52, 132. (b) Senguptya, K. K.; Aditya, S. Z. Phys. Chem. (Frankfurt am Main) 1963, $38,25$.

(25) Kasparek, G. J.; Bruice, T. C. Inorg. Chem. 1971, 10, 382.

(26) Brusa, M. A.; Perissinotti, L. J.; Colussi, A. J. J. Phys. Chem. 1985, $89,1572$.

(27) Brusa, M. A.; Perissinotti, L. J.; Colussi, A. J. Inorg. Chem. 1988, 27,4474 .

(28) Hanson, R. W. J. Chem. Educ. 1987, 67, 591.

(29) Young, I. B.; Trahanovsky, W. S. J. Am. Chem. Soc. 1969, 91, 5060 . 